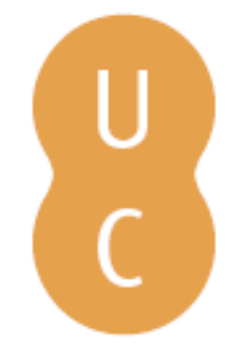

\title{
nombalina
}

\section{Ordenamento do território e riscos naturais: problemas sociais relacionados à desertificação no Município de Cabaceiras-PB}

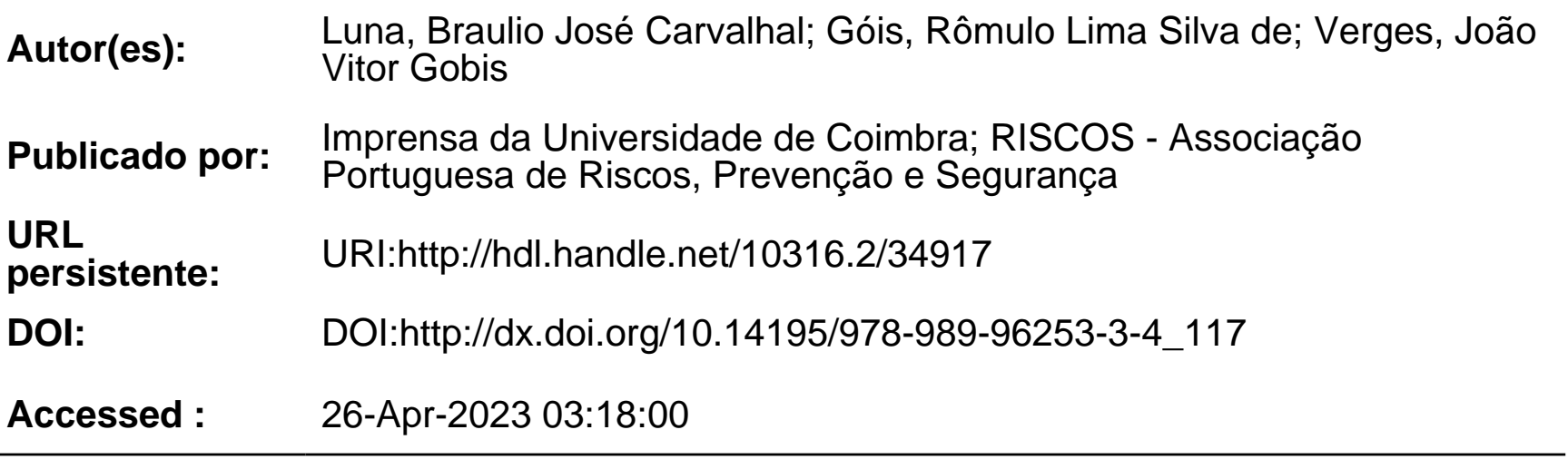

A navegação consulta e descarregamento dos títulos inseridos nas Bibliotecas Digitais UC Digitalis, UC Pombalina e UC Impactum, pressupõem a aceitação plena e sem reservas dos Termos e Condições de Uso destas Bibliotecas Digitais, disponíveis em https://digitalis.uc.pt/pt-pt/termos.

Conforme exposto nos referidos Termos e Condições de Uso, o descarregamento de títulos de acesso restrito requer uma licença válida de autorização devendo o utilizador aceder ao(s) documento(s) a partir de um endereço de IP da instituição detentora da supramencionada licença.

Ao utilizador é apenas permitido o descarregamento para uso pessoal, pelo que o emprego do(s) título(s) descarregado(s) para outro fim, designadamente comercial, carece de autorização do respetivo autor ou editor da obra.

Na medida em que todas as obras da UC Digitalis se encontram protegidas pelo Código do Direito de Autor e Direitos Conexos e demais legislação aplicável, toda a cópia, parcial ou total, deste documento, nos casos em que é legalmente admitida, deverá conter ou fazer-se acompanhar por este aviso.

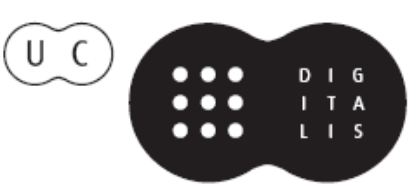



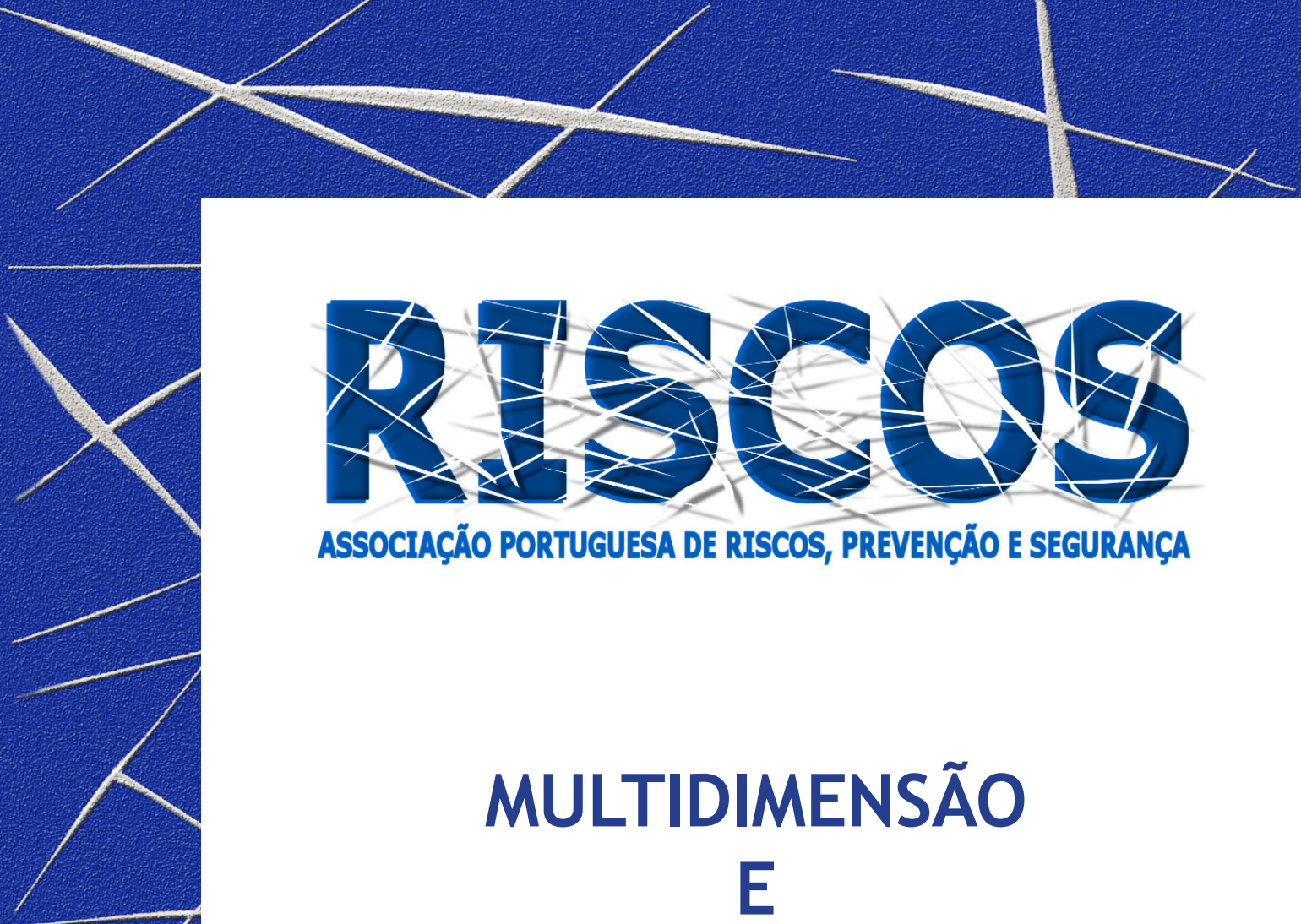

ASSOCIAÇÃO PORTUGUESA DE RISCOS, PREVENCCÃO E SEGURANÇA

MULTIDIMENSÃO

E
TERRITÓRIOS DE RISCO

III Congresso Internacional

I Simpósio Ibero-Americano

VIII Encontro Nacional de Riscos

Guimarães

2014 


\title{
ORDENAMENTO DO TERRITÓRIO E RISCOS NATURAIS: PROBLEMAS SOCIAIS RELACIONADOS À DESERTIFICAÇÃO NO MUNICÍPIO DE CABACEIRAS-PB
}

\author{
Braulio José Carvalhal Luna \\ Universidade de Lisboa, Universidade Nova de Lisboa, Faculdade de Ciências Sociais e Humanas
} bjcluna@hotmail.com

Rômulo Lima Silva de Góis

Univ. de Lisboa, Universidade Nova de Lisboa, Faculdade de Ciências Sociais e Humanas, Bolsista da CAPES n 1471-13-9 romulo.gois@yahoo.com.br

João Vitor Gobis Verges

Univ. de Lisboa, Universidade Nova de Lisboa, Faculdade de Ciências Sociais e Humanas, Bolsista da CAPES n ${ }^{9719-13-0}$ vitorverges@gmail.com

\begin{abstract}
RESUMO
Existem inúmeros indícios de que a mudança climática à nível mundial se apresenta de forma acelerada, fato que tem despertado o interesse da comunidade científica. Associada à essas mudanças, e potencializado pelas ações antrópicas, acrescenta-se o constante aumento da perda da qualidade produtiva dos solos pelo processo de desertificação. Exemplo desse processo ocorre no município de Cabaceiras-PB-Brasil, o que resulta em migração da população rural para os grandes centros urbanos. Neste processo, a pesquisa objetivou identificar os problemas sociais da população agrícola e como suas práticas tradicionais agravam o processo de desertificação. Nesse contexto, o trabalho tendo por base a pesquisa bibliográfica e dados secundários, visa traçar parâmetros de discursão entre a desertificação e os efeitos sobre a população economicamente vulnerável. Observou-se que as queimadas ainda constituem um processo no manejo dos recursos por parte dos agricultores, a monocultura e a consequente perda da biodiversidade restringem a utilização do solo para apenas um período do ano, tornando vulnerável nos demais períodos. A característica peculiar do ambiente com uma variação pluviométrica anual irregular é o fator agravante, e novas técnicas e alternativas ao uso do solo devem ser implementadas. Para além, políticas públicas locais, que possam designar partes territoriais através do ordenamento, visando entre outros fatores a organização e distribuição do espaço é outro fator que deve ser implantado.
\end{abstract}

Palavras-chave: Desertificação; Mudanças Climáticas; Riscos Sociais.

\section{Introdução}

Apesar dos sistemas humanos e naturais terem a capacidade de lidar com circunstâncias adversas, com a continuidade das mudanças climáticas a adaptação será necessária para manter esta capacidade (IPCC, 2014a).

Tendo como aspecto principal a mitigação, adaptação e resiliência nesse processo, inúmeras ferramentas políticas agem em determinadas regiões na pretensão de minimizar esses impactos, entre estes instrumentos podemos citar os Planos de Ordenamento e os Programas de incentivo dos Governos, compondo ações que buscam o uso racional do ambiente e a maximização do seu potencial produtivo.

Contudo, ferramentas políticas são utilizadas no município de Cabaceiras-PB-Brasil visando a minimização da perda da qualidade produtiva do solo pelo processo de desertificação, acentuado pelas frequentes ondas de calor proporcionadas pelas dinâmicas climáticas.

Nesse sentido a pesquisa objetivou identificar os problemas locais no âmbito social e ecológico e como ferramentas governamentais se efetivam no processo de adaptação do ambiente frente às dinâmicas climáticas tendo o Ordenamento do Território, um fator decisivo para esse processo. Para atingir tal objetivo, foram realizados levantamentos bibliográficos e de dados 
secundários, que forneceram subsídios para discursão dos efeitos climáticos local sob a população economicamente vulnerável, identificando os programas que inserem-se localmente com o intuito de promover o desenvolvimento econômico por meio de uma estratégia de desenvolvimento territorial sustentável.

\section{Enquadramento analítico}

\section{Ordenamento do Território}

A afirmação de que as mudanças climáticas são um fenómeno global, e afetam, em teoria, um número elevado de espaços e pessoas, rege o contexto teórico predominante. Mesmo tendo em vista que mudanças climáticas apresentam certas configurações globais, elas manifestam-se, espacialmente, em aspetos e intensidades distintas.

Como exemplo, podemos destacar o processo de desertificação, que de acordo com a Convenção para o Combate à Desertificação das Nações Unidas (UNCCD), é conceituado como a degradação da terra nas zonas áridas, semiáridas e sub-húmidas secas, que resulta de vários fatores, incluindo as variações climáticas e as atividades humanas.

Nesse contexto, o Ordenamento do Território (OT) surge como ferramenta crucial no processo de contribuição para aumentar a capacidade adaptativa das cidades e regiões face aos efeitos adversos das mudanças climáticas e atividades antrópicas, combatendo as ameaças e criando oportunidades.

\section{Metodologia}

Esta pesquisa se classifica como uma investigação de base teórica a partir de fontes primárias e secundárias, utilizando-se o método sistemático do conteúdo, através de levantamento bibliográfico de documentos oficiais e artigos.

O trabalho foi conduzido no município de Cabaceiras ( $07^{\circ} 29^{\prime} 20^{\prime \prime}$ Sul $36^{\circ} 17^{\prime} 13^{\prime \prime}$ Oeste), localizado na Mesoregião da Borborema e Microregião do Cariri Oriental, no estado da Paraíba, localizado na região Nordeste do território brasileiro, caracterizado pelo clima semi-árido e sujeito a estiagens prolongadas (IBGE, 2010). Composta de caatinga arbustiva, típica das regiões mais áridas do Nordeste, com cactos, arbustos e vegetação típicos

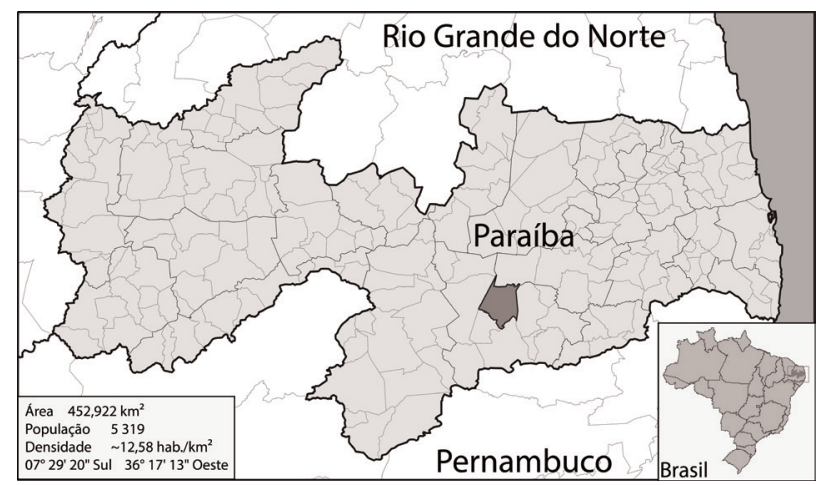

Figura 1 Mapa da Paraíba com destaque ao Município de Cabaceiras no estado da Paraíba. Fonte: (Paraíba, 2009) adaptado pelos autores. 
De acordo com o último senso realizado pelo Instituto Brasileiro de Geografia e Estatística (IBGE), no ano de 2013 sua população era estimada em 5.319 habitantes, distribuídos em uma área territorial de 452,922 km², o índice de desenvolvimento humano municipal em 2010 era de 0,611 (Brasil, 2014).

\section{Análise}

\section{Desertificação e os problemas locais}

No ambiente estudado, os processos que ocasionam a perda produtiva do solo, apresenta-se em um processo acelerado, ocasionado principalmente pelo índice pluviométrico irregular, associados a processos antrópicos, como queimadas, encabeçamento ineficiente e ao decapeamento do solo para construção civil.

Essas características são resultado, a longo prazo, de fatores políticos e económicos, relacionados com políticas específicas para os setores agrícola e florestal. Roxo, Mourão, and Casimiro (1998), ao analisar casos semelhantes em Portugal entendem que as políticas induzem mudanças que acabam por serem expressadas e relacionadas espacial e temporalmente, o que nem sempre se concretiza em efeitos benéficos ao ambiente.

Como forma de minimizar esses problemas na região, as ações governamentais através de programas e planos, e nelas incluídas o ordenamento do território, objetivam o desenvolvimento regional em seus diversos aspectos. No entanto, um dos maiores desafios à observação dos impactos da nas zonas rurais diz respeito às questões importantes de detecção e atribuição desses impactos às mudanças climáticas (IPCC, 2014b).

Embora no meio acadêmico e científico seja evidente que certas práticas agrícolas acelerem os impactos negativos locais, ocasionados ou potencializados pelos regimentos climáticos, é necessário, também, um processo de afirmação da educação ambiental e a associação entre novas técnicas potencializadoras da agroecologia, para que estas sejam adotadas com destreza pelos agricultores. Neste processo, haveria uma associação profícua entre o saber regional/ local e as novas necessidades da abordagem climática global.

Os problemas na identificação consiste no fato de que a variabilidade e mudanças climáticas interagem com as pressões de subsistência existentes na zona rural, com a política econômica, a globalização, a degradação ambiental e questões de saúde, como tem sido demonstrado em diversos países (IPCC, 2014b).

Para limitar a vulnerabilidade, são necessários ações integradas que visam uma redução das múltiplas pressões não relacionados ao clima sobre os recursos naturais, nomeadamente, vegetação, solo e água, como por exemplo as queimadas, poluição da água doce, desmatamento, encabeçamento acima da capacidade de suporte. Neste caso, a integração efetiva entre as populações campesinas, mediando o acesso real às informações e técnicas, deve compor os planos e ações junto aos drivers das intencionalidades de mitigação e adaptação ao clima.

\section{Programas governamentais locais - Território da Cidadania}

Devido às características da região, no que diz respeito ao desenvolvimento económico e social, programas governamentais que procuravam promover o fortalecimento e desenvolvimento do território com o objetivo de diminuir as desigualdades regionais do país foram implantados de forma a firmar a gestão territorial. 
Nessa perspectiva essas políticas públicas têm influenciado a região ao longo do tempo, refletindo diretamente nas atividades agropecuárias e nas dinâmicas populacionais locais. As políticas atuavam diretamente na alternância e convivência de culturas e o local ocupado pelo pequeno produtor (Caniello et al., 2011).

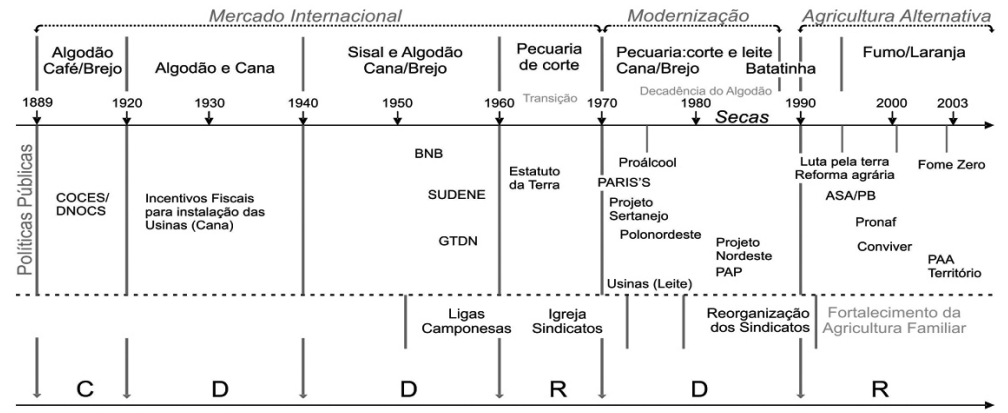

Figura 2 Influência das políticas no agreste Paraibano. Legenda: C - Campesinização; D Descampesinização; R - Recampesinização. Fonte: Piraux e Miranda (2011, apud Caniello et al., 2011).

Nesse contexto o Governo Federal do Brasil lançou, em 2008, o Programa Territórios da Cidadania em diversas regiões do país, elencando entre outras a região analisada. O programa vem gradativamente atingindo seus objetivos que são de promover o desenvolvimento econômico e universalizar projetos básicos de cidadania por meio de uma estratégia de desenvolvimento territorial sustentável, considerando para o êxito estratégico a participação social e a integração de ações entre todas as esferas do governo (Brasil, 2014).

\section{Conclusão}

Os programas e ações do governo no município aumentam a comercialização da produção agrícola, mas no que concerne os problemas relacionados a perda da qualidade produtiva do solo, não apresentam maneiras efetivas de minimizar o aumento gradativo dessas áreas improdutivas.

Para limitar a vulnerabilidade às ações antrópicas na região, são necessárias ações integradas, que visam uma redução das múltiplas pressões não relacionadas ao clima sobre os recursos naturais, como por exemplo as queimadas, poluição da água doce, desmatamento e encabeçamento acima da capacidade de suporte.

\section{Referências Bibliográficas}

Brasil, M. F. (2014). Portal da Cidadania. Retrieved 09/06/2014, 2014, from http: / / www.territoriosdacidadania. gov.br/

Caniello, M. d. M., Bastos, V. V. d. S., Martins, M. D. F., Piraux, M., Cantalice, L. R., Nunes, T. L., \& Torres, J. V. O. (2011). Acompanhamento, monitoramento e avaliação da evolução e qualidade dos resultados do Programa Desenvolvimento Sustentável De Territórios Rurais - PDSTR no Território da Borborema (Paraíba) (C. d. A. e. I. d. T. d. Borborema, Trans.) (Vol. 1, pp. 189): Universidade Federal de Campina Grande.

Ferrão, J. (2011). O ordenamento do território como política pública (Vol. 1): Ed. Fundação Calouste Gulbenkian. 
Ferrão, J. (2014). Alterações Climáticas e Ordenamento do Território. Universidade Nova de Lisboa: Slide de Aula.

Ferrão, J., \& Mourato, J. M. (2012). Evaluation and spatial planning in Portugal: from legal requirement to source of policy-learning and institutional innovation De la Evaluacion Ambiental Estrategica a la Evaluacion de Impacto Territorial: Reflexiones acerca de la tarea de evaluacion PUV - Universitat de València.

IBGE, I. B. d. G. e. E. (2010). IBGE Cidades@. Retrieved 11 de outubro de 2013, 2013, from http://www. ibge.gov.br/cidadesat/topwindow.htm?1

IPCC, I. P. o. C. C. (2014a). Adaptation Needs and Options In: Climate Change 2014: Impacts, Adaptation, and Vulnerability. (5). Retrieved from http://www.ipcc.ch/.

IPCC, I. P. o. C. C. (2014b). Rural Areas In: Climate Change 2014: Impacts, Adaptation, and Vulnerability. (9). Retrieved from http://www.ipcc.ch/.

Paraíba, A. E. d. G. d. Á. d. E. d. P.-A. (Cartographer). (2009). Sistema de Coodenadas Geográficas Microregiões da Paraíba. Retrieved from http://www.aesa.pb.gov.br/

Roxo, M. J., Mourão, J. M., \& Casimiro, P. C. (1998). Políticas agrícolas, mudanças de uso do solo e degradação dos recursos naturais - Baixo Alentejo Interior. Mediterrâneo, 12/13, 23. 